\title{
Monitoring turbidity in the Ionical coast during extreme events by applying a Robust Satellite Technique (RST) to MODIS imagery
}

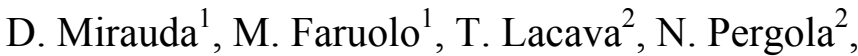 \\ G. Spilotro ${ }^{3} \&$ V. Tramutoli ${ }^{1}$ \\ ${ }^{1}$ D.I.F.A., University of Basilicata, Italy \\ ${ }^{2}$ (IMAA) - National Research Council (CNR), Tito Scalo (PZ), Italy \\ ${ }^{3}$ D.I.S.G., University of Basilicata, Potenza, Italy
}

\begin{abstract}
Monitoring of Suspended Sediment Concentrations in plumes (SSC) at river mouths is particularly important for a correct sediment balance. Such evaluation requires the knowledge of many hydraulic and hydro-geological factors, highly variable in the space-time domain and not easily measurable through conventional techniques. Mainly because of this, satellite techniques have been proposed to allow the monitoring of SSC space-time dynamics with spatial resolution ranging between 250 and 3000 meters and time repetition from a few hours up to a few minutes.

This paper presents a first attempt to apply the general Robust Satellite Technique (RST) approach, already used to investigate several natural and environmental hazards, for SS detection and mapping. Preliminary achieved results seem to confirm that such approach is suitable for automatically identifying the spectral signatures of different suspended particle mixtures, taking into account bathymetric effects, which might mask the presence of sediments near the coasts. A preliminary, qualitative integration of ground-based data and measurements (e.g. water levels and discharges) with satellite-based information is also proposed as a first step toward a further methodology suggested for a full data integration strategy.

Ground-based and satellite derived information, based on Moderate Resolution Imaging Spectroradiometer (MODIS) imagery, are combined in the cases of the flood events occurred on 28 March 2007 and 11 March 2010 along the Ionical coast of Basilicata Region, in Southern Italy.
\end{abstract}


Keywords: suspended sediment concentration, RST, MODIS, water level, water discharge, flood event.

\section{Introduction}

Suspended sediment concentration (SSC) is an important parameter to estimate and predict soil erosion and sediment transport at river mouths and in coastal areas. SSC data are also essential to understand water quality, because suspended sediments can control the transport of nutrients, the reduction of light penetration and fluxes of metals, the productivity of submerged aquatic vegetation and phytoplankton, the coral growth, the radio-nuclides and organic micropollutants. The distribution and flux of suspended sediments are highly variable in coastal environments and vary over a broad spectrum of time and space scales (e.g. Miller and McKee [1]).

Methods currently used for the in situ measurement of SSC are costly and time-consuming (e.g. Gao and O'Leary [2]). With these methods, SSCs are measured only at gauged stations or through field surveys. Temporally, many return visits are required to provide long-term or continuous data. Spatially, the number of gauged stations and field survey sites are limited due to high costs and inaccessibility. As a result, it is difficult to accurately map spatial variations in SSC over a large area (e.g. Nanu and Robertson [3]).

The difficulties, above exposed, have pushed different researchers toward the use of alternative methods of acquisition and elaboration to be integrated with data and information coming from in situ measurements, especially when there is a demand of continuous observations, both in temporal and spatial domains.

Satellite remote sensing may provide a viable alternative option to retrieve SSC data, thanks to the synoptic view offered by space systems, and because of the spectral/spatial/temporal resolutions that present satellite missions may guarantee.

Space-based SSC observations have been already performed since the Landsat 1 launch (e.g. Kritikos et al. [4]). They are generally based on the increase of clear water reflectance in the Visible - Near Infrared spectral region (VNIR), caused by the presence of suspended sediments (e.g. Acker et al. [5] and references therein). This approach is reasonably robust in coastal and inland waters because scattering from suspended materials frequently dominates the reflectance spectra when compared to pure water and phytoplankton absorption (e.g. Mobley [6]).

Empirical, semi-analytical and analytical approaches have been adopted up to now to retrieve SSC from ocean colour data coming from different satellite sensors (e.g. Acker et al. [5]; D'Sa et al. [7], Nechad et al. [8], Xi and Zhang [9] and references therein). Among the space-borne optical sensors able to furnish reliable SSC measurements, the Moderate-resolution Imaging Spectroradiometer (MODIS) instrument on-board of Terra and Aqua Earth Observing System EOS satellites is the one which offers the best trade-off between spatial and temporal resolution, useful especially as far as monitoring purposes are needed (e.g. Miller and McKee [1]). MODIS, in fact, guarantees up to two global daily diurnal 
acquisitions at no cost, with a spatial resolution up to $250 \mathrm{~m}$ in the first two channels (VNIR region). MODIS began providing science data in February 2000 and June 2002 for the Terra and Aqua EOS satellites, respectively.

Different studies have already used MODIS data measured in the VNIR spectral region to estimate SSC. Both single channel (e.g. Chen et al. [10], Petus et al. [11]) and multi-channel combination methods (e.g. Doxaran et al. [12], Hu et al. [13], Mobasheri [14], Zhang et al. [15]) have been proposed for the retrieval of total suspended matter in coastal areas. As most of those previous studies demonstrated, MODIS band 1, providing coverage in the red spectral region $(620-670 \mathrm{~nm})$ at a sufficient sensitivity, with a spatial resolution of $250 \mathrm{~m}$ and near daily coverage, may be well suited for examining suspended particulates in coastal environments. However, some authors, although recognizing this spectral channel as the most suitable (because of its high penetration capacity) for such a purpose, identified issues related to the applicability of algorithms in shallow waters (e.g. inshore), due to bottom reflection effects (e.g. Li et al. [16]).

This study applies for the first time the general Robust Satellite Technique (RST) approach (e.g. Tramutoli [17]) to VNIR MODIS satellite images to estimate SS content in the case of flood events occurred along the Ionian coast of Basilicata Region, in southern Italy. RST approach is proposed because of its intrinsic independence on bathymetric effects in shallow waters, which, as mentioned above, might limit other single image analysis algorithms.

This work is also intended as a feasibility study for a preliminary assessment of the added value achievable by integrating satellite products and ground-based measurements, investigating possible correlations between such heterogeneous and independent information. In particular, this paper represents a first step toward a fully integrated approach, where local hydraulic measurements might be correlated to $2 \mathrm{D}$ satellite information, to verify whether from in situ data collected at rivers (i.e. local measurements), reliable estimations of suspended sediments in coastal areas (i.e. spatial information) might be inferred.

To this aim, two different case studies are investigated here, one related to an over-threshold event, occurred in March 2010, the other in correspondence of an ordinary (under-threshold) event (happened in March 2007).

\section{Investigated area}

The study area is the Ionical coast of Basilicata region, in southern Italy, which has a length of 45 kilometers (fig. 1). The coast, of a variable 10 to 100 meters width, is characterized by low and sandy beaches, sometimes pebbly, and sandy sea-beds with an expanded bar zone. It is delimited by dunes, which progress parallel to the coastline, with a 1-2 kilometers' width and characterized by the development of psammophila vegetation and residual patches of the original coastal lowland forest.

Five rivers flow into the coast along the investigated area: Sinni, Agri, Cavone, Basento and Bradano. Their sedimentation has shaped the Metaponto Plain, which has undergone an anthropization process in the last century and 
today represents a high environmental and historical-cultural interest area for Basilicata, as well as economic, as it is a flourishing area for the development of its agricultural and touristic activities, linked to the presence of archeological sites and seaside resorts.

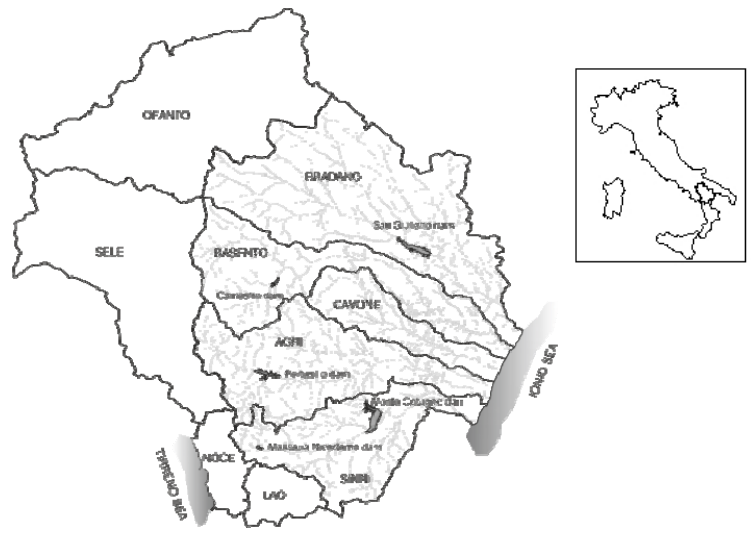

Figure 1: $\quad$ The investigated area.

In the last years the Ionical coast have been subject to retreating phenomena indicated by a shift of the river mouth and a dismantling of the original dunes. In particular, between 1996 and 1999 the Basento mouth moved southwards of about 200-250m (fig. 2) and the Bradano mouth moved northwards of about $100 \mathrm{~m}$ (fig. 3), causing extensive erosion phenomena on the adjacent coastlines.

One of the causes of such coastline retreating could be the reduction of the solid discharge due to material removal by the biggest dams built between the 1960s and 1970s on the Bradano, Basento, Agri and Sinni rivers (fig. 1). In fact, as outlined in several studies (e.g. Molino [18]), the average evaluation of the annual soil trapping in the main reservoirs of the region amount up to $300.000 \mathrm{~m}^{3} / \mathrm{y}$, with obvious effect on the river and costal evolution (e.g. Greco et al. [19]).

In the case of the Bradano, the biggest dam is that of S. Giuliano, with a total capacity of 107 million cubic metres. It is located at about $40 \mathrm{~km}$ away from the coast. The biggest dam of the Basento, named Camastra, with a total capacity of

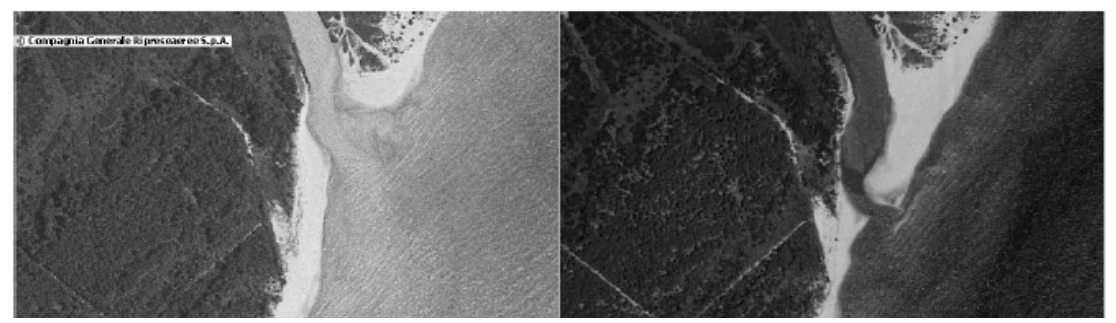

a)

b)

Figure 2: Comparison between the aerial photos of the Basento river delta relative to the flights 1999 (a) and 1994 (b). 


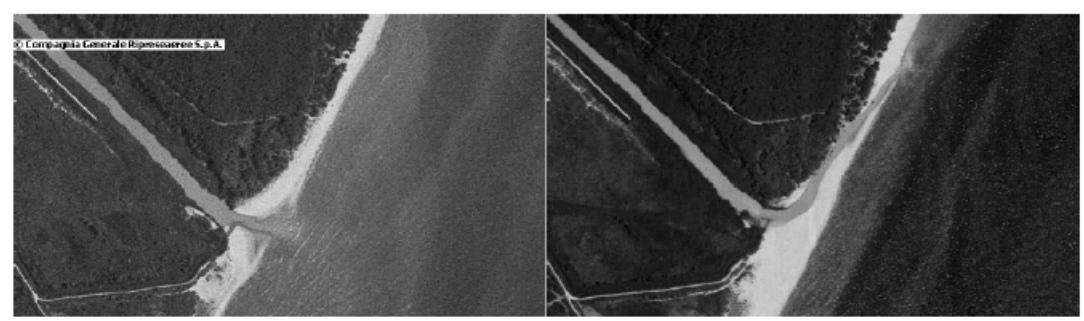

a)

b)

Figure 3: Comparison between the aerial photos of the Bradano river delta relative to the flights 1999 (a) and 1994 (b).

about 24 million cubic meters, was built not on the main river course, but on its right tributary.

In mid-course of the Agri we find the Pertusillo dam, about $70 \mathrm{~km}$ away from the coast, which has a capacity of about 155 million cubic meters of water for irrigation, hydroelectric and drinking use.

Along the Sinni, the dams of Monte Cotugno and Masseria Nicodemo were built. The dam of Monte Cotugno, about $35 \mathrm{~km}$ from the coast, represents the nodal point of the whole water system. Built in soil and with a total capacity of about 450 million cubic meters, also receives contributions from the Agri's basin. The dam of Masseria Nicodemo, with a total capacity of about 10 million cubic meters, intercepts the waters of the Sinni upstream. Both the dams hold back the solid material supplied from the upstream and therefore they modify in some measure the configuration of the river bed in the valley. The course of the Cavone River is not interested by any type of dam. Other causes of the coastline retreating in the area are the extractive activity on the river bed, particularly intense between 1965 and 1992, official extractions having been allowed of 9.0 and 5.9 million $\mathrm{m}^{3}$ materials from the Basento and Bradano rivers; the regime of the wave-motion which moves the sediment from the beach and partly carries it towards deep waters; the building of conduits, banks, hydraulic defense works, etc.; the excessive pumping of the groundwater, with subsequent subsidence phenomena; the realization of touristic settlements.

Besides, the presence of the dams and the fine granulometry of the rivers in the valley part results in sand and silt sediments moved to the mouth during flood events.

Therefore, the river mouths of the Ionical coast of Basilicata are affected by the development of suspended sediment plumes during relevant flood events.

\section{Data and methods}

The satellite images analysis has been integrated with in situ measures of water levels and discharges coming from gauged sections located along the Basento, Agri and Sinni rivers.

The localization of the gauged sites is reported in fig. 4. As it is possible to note in the figure, the Torre Accio (Basento) station and the Sinni S.S. 106 
(Sinni) one are placed at a short distance from the river mouth, while that of Ponte La Marmora (Agri) is located on the downstream of the Pertusillo dam. Unfortunately the Agri hasn't been monitored in the final part of its course and the Ponte La Marmora station is the closest to the mouth.

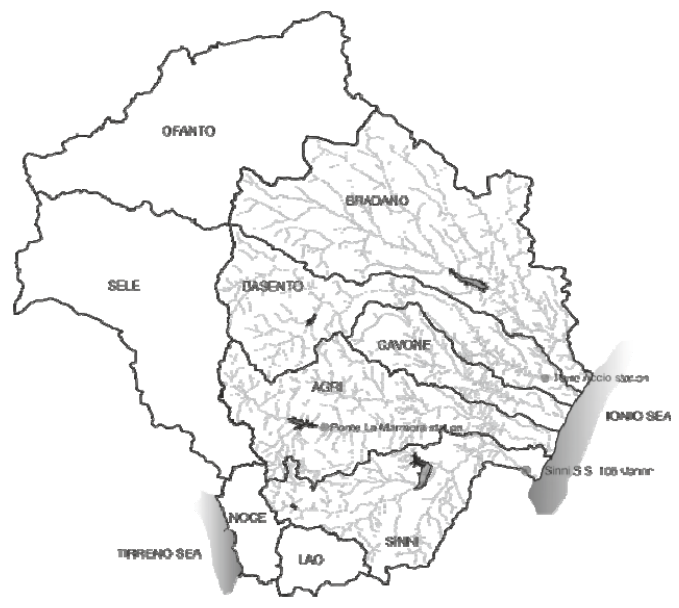

Figure 4: Localization of the gauged sections.

The water levels are recorded in continuous by ultrasonic hydrometers managed by the Regional Agency for the Protection of the Environment (A.R.P.A.B).

The water discharges, instead, have been estimated through the rating curves built after large field measures carried out by Basilicata University and A.R.P.A.B (e.g. Mirauda et al. [20]).

Regarding satellite data, MODIS channel 1 (VIS) records have been used, because of its spectral and spatial characteristics. In order to implement the RST approach, the following local variation index has been computed:

$$
\otimes_{V I S}(x, y, t)=\frac{R_{V I S}(x, y, t)-\mu_{V I S}(x, y)}{\sigma_{V I S}(x, y)}
$$

where:

$R_{V I S}(x, y, t)$ is the reflectance measured in the MODIS VIS band, computed at pixel level (at location $x, y$ ) on the satellite image at hand (acquired at time $t$ ); $\mu_{V I S}(x, y)$ is the temporal average and $\sigma_{V I S}(x, y)$ the standard deviation of $R_{V I S}(x, y, t)$, both computed, at pixel level, by stratifying multi-years, homogeneous MODIS VIS images (i.e. acquired in the same month of the year and at the same hour of pass), to build expected value and natural variation of sea reflectance, under normal or unperturbed conditions.

For the background reference fields' computation, 989 MODIS images, all acquired between $9.30-13.00 \mathrm{GMT}$, in the month of March, have been collected and processed in this study, analyzing a time period of 8 years, from 2003 to 2010. An area of interest of $600 \times 600$ pixels, centered at $40^{\circ} 15^{\prime}$ Latitude $\mathrm{N}-$ 
$16^{\circ} 14^{\prime}$ Longitude E, was extracted from each satellite scene and re-projected in the same Geographic projection (Lat-Lon, WGS84). An iterative, k-sigma clipping procedure (e.g. Tramutoli [17]) has been also applied to remove possible outliers form the used time series. In addition, cloudy pixels, identified by using an original cloud detection scheme (e.g. Cuomo et al. [21]), have been excluded and not longer used for reference fields and $\otimes_{V I S}$ index computation.

Therefore, as well as the MODIS channel $1(0.55-0.86 \mu \mathrm{m})$ excess reflectance beyond the power law values can be associated to the presence of suspended sediments (e.g. Li et al. [16]), Suspended Sediments (SS) plumes should be automatically identified by RST as space-time sea reflectance statistically significant anomalies (i.e. with $\otimes_{V I S}>2$ ), with intensities and extents that should depend on SS concentration and amount.

\section{Discussion of the results}

As before mentioned, two different events, occurred in the Basilicata region, have been considered for this study. The first one, occurred on 10 March 2010, was a very intense flood, interesting large territories and producing several inundations mainly in the Metaponto Plain. The whole Ionical coast was interested by strong sea storms. On the other hand, the event occurred at the end of March 2007 was a minor one, with water levels and discharges never reaching the alert threshold values. It may be classified as an "ordinary" event.

To analyze the two events for each gauged station, the trend of the maximum daily water levels in the months of March 2007 and 2010 is reported in fig. 5.
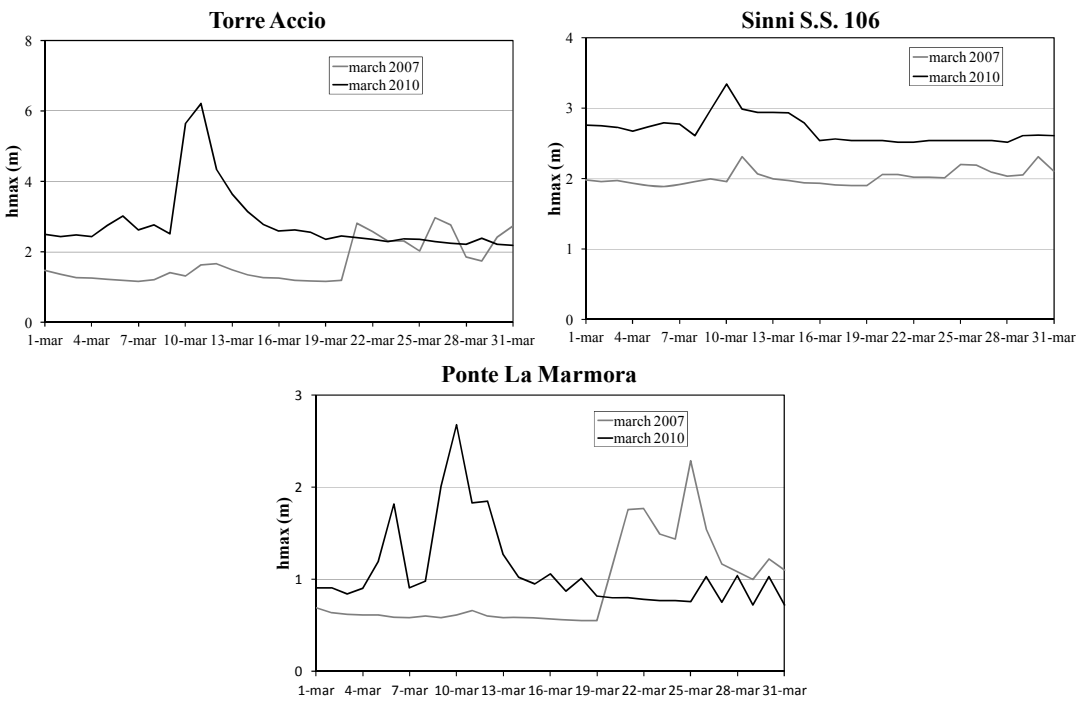

Figure 5: Trends of the maximum daily water levels in the months of March 2007 and 2010 during flood events. 
As we can see, the maximum levels are reached in 2010, being of $6.21 \mathrm{~m}$ for the Torre Accio station, 3.34 for the Sinni S.S.106 and 2.68 for the Ponte La Marmora stations, on the days of 10-11 March. In all three sections the levels of alert are overcome, representing the value limit of the depth beyond which a control system able to safeguard the populations from flood events is activated. In particular, the level of alert for the Torre Accio station is of about $3.5 \mathrm{~m}$ while for the Ponte La Marmora station is about $2.5 \mathrm{~m}$.

By the end of March 2007, instead, lower levels are observed in all stations and in this occasion alert thresholds are not reached. For this reason this case can be considered as an ordinary event.

The results of the water level trend observations are confirmed by the values of the discharges evaluated through the rating curves and reported in fig. 6 .
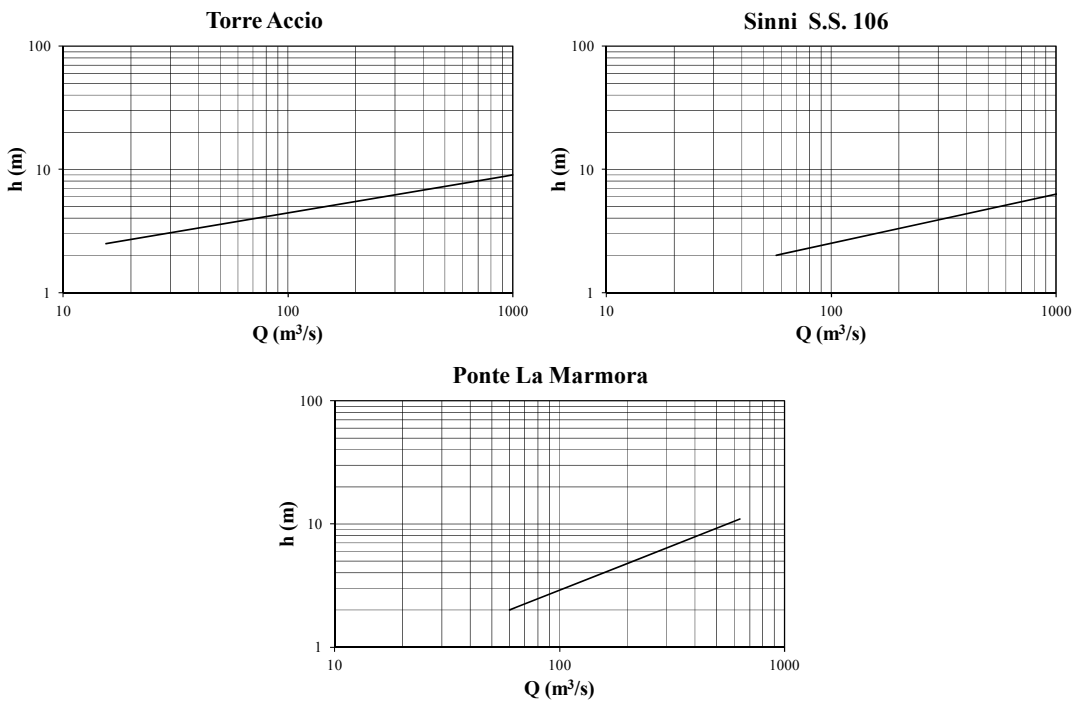

Figure 6: The rating curves of flood represented in bi-logarithmic scale.

The following table reports for every value of peak level observed in 2007 and 2010 the corresponding value of discharge.

The water discharges of Torre Accio and Sinni S.S. 106 are superior to $200 \mathrm{~m}^{3} / \mathrm{s}$ confirming the intensity of the event in March 2010, compared to that verified in March 2007. The same is true for Ponte La Marmora, where the value of $90 \mathrm{~m}^{3} / \mathrm{s}$ overcomes the average of the maximum annual discharges at flood

Table 1: $\quad$ Values of water levels and discharges during the flood events.

\begin{tabular}{|l|c|c|c|c|}
\cline { 2 - 5 } \multicolumn{1}{c|}{} & \multicolumn{2}{c|}{$\mathbf{2 0 0 7}$} & \multicolumn{2}{c|}{$\mathbf{2 0 1 0}$} \\
\hline Gauged section & $\mathbf{h}_{\max }(\mathbf{m})$ & $\left.\mathbf{Q} \mathbf{( m}^{\mathbf{3}} / \mathbf{s}\right)$ & $\mathbf{h}_{\max } \mathbf{( m )}$ & $\left.\mathbf{Q} \mathbf{~ m}^{\mathbf{3}} / \mathbf{s}\right)$ \\
\hline Torre Accio (Basento) & 2,97 & 27,2 & 6,21 & 298,6 \\
\hline Sinni S.S. 106 (Sinni) & 2,31 & 81,8 & 3,34 & 206,3 \\
\hline Ponte La Marmora (Agri) & 2,29 & 72,4 & 2,68 & 90 \\
\hline
\end{tabular}


peak recorded through the years in the upstream, which is around $85 \mathrm{~m}^{3} / \mathrm{s}$ (e.g. Claps et al. [22]).

According to event occurrences, MODIS imagery acquired after the date of measured maximum river levels and discharges has been investigated. With reference to the major event, occurred on 10-11 March 2010, the first cloud-free MODIS image over the area of interest was acquired on 15 March 2010, at 09.05GMT (Fig. 7-left), 5 days later. Following RST approach, the $\otimes_{\text {VIS }}$ index from eqn. (1) has been computed over the area of interest. Detected space-time anomalies of reflectance are reported in fig. 7 (right-side).
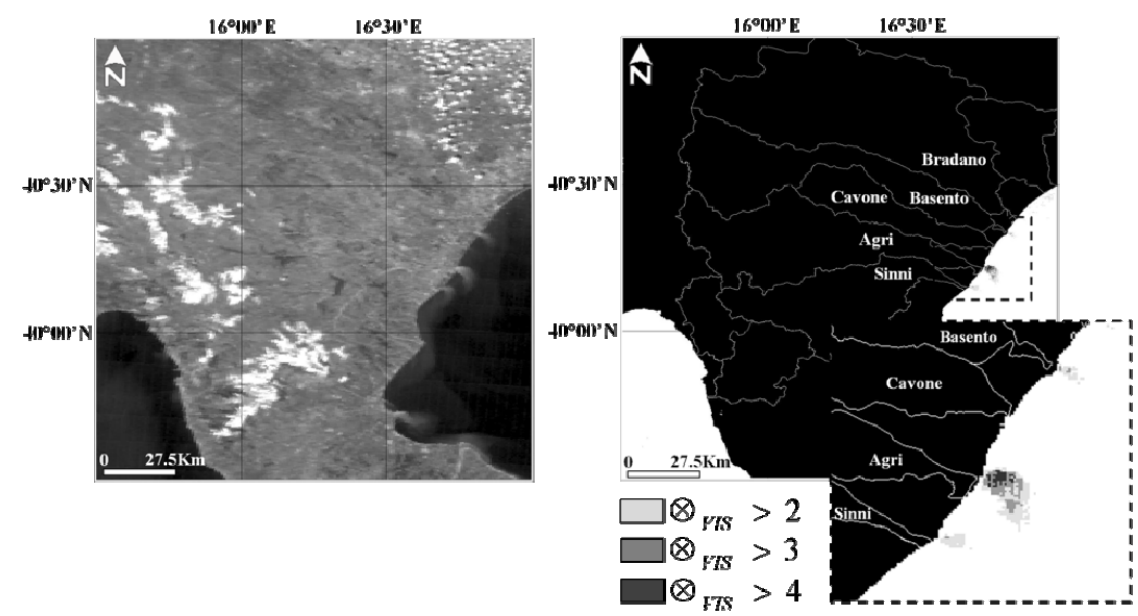

Figure 7: Left - MODIS VIS image acquired on 15 March 2010; Right - Map of detected space-time reflectance anomalies, with different intensities. Land areas are masked and reported in black.

Looking at the figure, it is possible to note how significant reflectance excess was observed in correspondence of the Basento, Agri and Sinni basins. It should be noted that reflectance excesses were automatically identified and detected also inshore, where bathymetric effects are generally significant. In particular, the Agri space-time anomaly is the biggest one, with an estimated spatial extent of more than $20 \mathrm{~km}^{2}$ (as far as $\otimes_{\mathrm{VIS}}>2$ areas are considered) and a relative intensity of the reflectance excess up to 6 times the normal variability, with about 40 pixels having $\otimes_{\text {VIS }}>4$. In comparison, anomalous areas detected (with $\otimes_{\text {VIS }}$ $>2$ ) at the Basento and Sinni river mouths have estimated extents of about $2 \mathrm{~km}^{2}$ and $3 \mathrm{~km}^{2}$, respectively.

This result is in agreement with what observed from level and discharge measures in the gauged fluvial stations. In particular, the significant reflectance at Agri mouth signals the presence of suspended sediment transported from the extraordinary flood happened in those days. The same is true for the Basento mouth also if the signal intensity is low; this could be due to sediment stored in the final part of the river. The minor content of suspended sediment at the Sinni mouth is due to the presence of the Monte Cotugno dam and to the presence of a 
gabion built in 2004 downstream of the Sinni S.S. 106 station which contribute to trap the sediment.

With regard to the March 2007 case study, as before mentioned, this was not an over-threshold event, thus no comparable effects have to be expected at river mouths in this case. Like before, MODIS VIS cloud-free images available after the date of measured peaks in hydraulic level and discharge (see figs. 5 and 6) were considered and, to make results more comparable, passes acquired with 4-6 days of delay were processed. One suitable MODIS pass was found, acquired on April the 1st, 2007 at 12.20GMT (Fig. 8-left), again 5 days later than the maximum levels measured by in situ stations. Similarly, fig. 8 reports the derived map of intensity and spatial distribution of SS, as detected by RST.

As expected, no comparable anomalies were detected for all river mouths, as a confirmation of the low intensity of this study case.
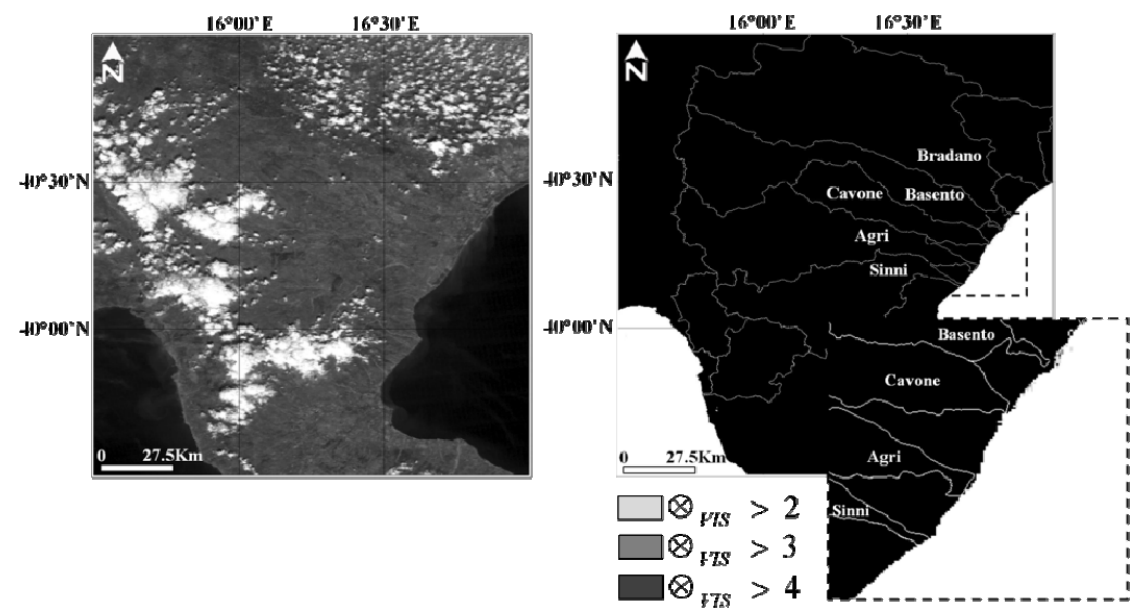

Figure 8: $\quad$ As figure 7 for the MODIS image acquired on 1 April 2007 at12:20GMT over the investigated area.

\section{Conclusions}

This paper describes a first attempt to apply the general Robust Satellite Technique (RST) approach, already used for investigating several natural and environmental hazards, for the analysis of Suspended Sediment Concentrations at river mouths. A preliminary, qualitative integration of water levels and discharges with satellite-based information has been proposed. Such a procedure has been applied to two different flood events, one occurred in March 2010 and the other, a minor one, happened in March 2007.

The obtained results confirm that such an approach is suitable to automatically identify the spectral signatures of different suspended particle mixtures near the coast. In particular, in the case of strong intensity events like that of 11 March 2010 the achieved, RST-based, SS content map shows anomalous reflectance signals in correspondence of the three river mouths, with 
higher intensities and larger extent at the Agri mouth. The minor levels (both in intensity and size) of detected anomalies at mouths of other rivers are due to the different interventions carried out along the watercourse and to the different hydrodynamic behavior of the flow. No significant anomalies are detected in the case of an ordinary event, confirming the qualitative correlation of satellite and in situ measurements, and proving the usefulness of satellite derived maps to infer flood event intensity and severity.

Finally, the RST approach confirmed to be applicable inshore, where bathymetric effects are generally important and might limit the reliability of traditional, one-channel and single-image techniques.

\section{Acknowledgements}

The authors thank Dr. Carlo Glisci of the Regional Agency for the Protection of the Environment (A.R.P.A.B) for his assistance during the ground-based data researching phase.

\section{References}

[1] Miller, R.L., \& McKee, B.A., Using MODIS Terra $250 \mathrm{~m}$ imagery to map concentrations of total suspended matter in coastal waters, Remote Sensing of Environment, 93, 259-266, 2004.

[2] Gao, J., \& O'Leary, S.M., Estimation of suspended solids from aerial photographs in a GIS, International Journal of Remote Sensing, 18, 2073-2086, 1997.

[3] Nanu, L., \& Robertson, C., Estimating suspended sediment concentrations from spectral reflectance data, International Journal of Remote Sensing, 11, 913-920, 1990.

[4] Kritikos, H., Yorinks, L., \& Smith, H., Suspended solids analysis using ERTS-A data, Remote Sensing of Environment, 3, 69-78, 1974.

[5] Acker, J., Ouillon, S., Gould, R., \& Arnone, R., Measuring Marine Suspended Sediment Concentrations from Space: History and Potential, Proceedings of the 8th International Conference on Remote Sensing for Marine and Coastal Environments, Halifax, NS, Canada, May 17-19, 2005.

[6] Mobley, C. D., Light and water: Radiative transfer in natural waters, San Diego, CA7 Academic Press, Inc., 1994.

[7] D’Sa, E.J., Miller, R.L., \& McKee, B.A., Suspended particulate matter dynamics in coastal waters from ocean color: Application to the northern Gulf of Mexico, Geophysical Research Letters, 34, L23611, doi:10.1029/2007GL031192, 2007.

[8] Nechad, B., Ruddick, K.G., \& Park Y., Calibration and validation of a generic multisensor algorithm for mapping of total suspended matter in turbid waters, Remote Sensing of Environment, 114, 854-866, 2010.

[9] Xi, H., \& Zhang, Y., Total suspended matter observation in the Pearl River estuary from in situ and MERIS data, Environ. Monit. Assess., 177, 563-574, 2011. 
[10] Chen, Z., Hu, C., \& Muller-Karger, F., Monitoring turbidity in Tampa Bay using MODIS/Aqua 250-m imagery, Remote Sensing of Environment, 109, 207-220, 2007.

[11] Petus, C., Chust, G., Gohin, F., Doxaran, D., Froidefond, J. M., \& Sagarminaga, Y., Estimating turbidity and total suspended matter in the Adour River plume (South Bay of Biscay) using MODIS 250-m imagery, Continental Shelf Research, 30, 379-392, 2010.

[12] Doxaran, D., Froidefond, J.M., \& Castaing, P., A reflectance band ratio used to estimate suspended matter concentrations in sediment-dominated coastal waters, Int. J. Remote Sensing, 23, 5079-5085, 2002.

[13] Hu, C., Chen, Z., Clayton, T. D., Swarzenski, P., Brock, J.C., \& MullerKarger, F. E., Assessment of estuarine water-quality indicators using MODIS medium-resolution bands: Initial results from Tampa Bay, FL, Remote Sensing of Environment, 93, 423-441, 2004.

[14] Mobasheri, M. R., Assessment of Suspended Sediments Concentration in Surface Waters, Using Modis Images, American Journal of Applied Sciences 5, 798-804, 2008.

[15] Zhang, M., Tang, J., Dong, Q., Song, Q., \& Ding, J., Retrieval of total suspended matter concentration in the Yellow and East China Seas from MODIS imagery, Remote Sensing of Environment, 114, 392-403, 2010.

[16] Li, R., Kaufman, Y.J., Gao, B., \& Davis, C. O., Remote Sensing of Suspended Sediments and Shallow Coastal Waters, IEEE Transactions on Geoscience and Remote Sensing, 41, 2003.

[17] Tramutoli, V., Robust Satellite Techniques (RST) for natural and environmental hazards monitoring and mitigation: ten years of successful applications, The 9th Int. Symposium on Physical Measurements and Signatures in Remote Sensing, Shunlin Liang, Jiyuan Liu, Xiaowen Li, Ronggao Liu, Michael Schaepman Editors, Beijing (China), ISPRS, XXXVI (7/W20), 792-795, ISSN 1682-1750, 2005.

[18] Molino, B., Silting up of artificial reservoirs: Defense strategies Sediment management, International Workshop: Ecological, sociological and economic implications of sediment management in reservoirs, Prignano Cilento, 2002.

[19] Greco, M., Mauro, A, Mirauda, D., Sole, A., \& Vita, M., Integrated monitoring system of littoral and fluvial sediment transport in Basilicata, Coastal Environment 2004 Fifth International Conference on Environmental Problems in Coastal Regions, Alicante, Spain, 10, 199207, 2004.

[20] Mirauda, D., Greco, M. \& Moscarelli, P., Practical methods for water discharge measurements in fluvial sections, River Basin Management 2011, Riverside, USA, 2011.

[21] Cuomo, V., Filizzola, C., Pergola, N., Pietrapertosa, C., \& Tramutoli, V., A self-sufficient approach for GERB cloudy radiance detection, Atmospheric Research, 72, 39-56, 2004.

[22] Claps, P., Fiorentino, M., \& Laio, F., Scale di deflusso di piena di corsi d'acqua naturali, La difesa idraulica del territorio, Trieste, 2003. 